\title{
COVID-19 in cladribine-treated relapsing-remitting multiple sclerosis patients: a monocentric experience
}

\author{
Paolo Preziosa ${ }^{1,2} \cdot$ Maria A. Rocca ${ }^{1,2,5} \cdot$ Agostino Nozzolillo $^{2} \cdot$ Lucia Moiola $^{2} \cdot$ Massimo Filippi $^{1,2,3,4,5}$
}

Received: 27 August 2020 / Revised: 2 November 2020 / Accepted: 8 November 2020 / Published online: 20 November 2020

(c) Springer-Verlag GmbH Germany, part of Springer Nature 2020

Dear Sirs,

Cladribine is a purine nucleoside analog that inhibits DNA synthesis and repair in highly dividing cells inducing B- and T-cell apoptosis [1]. Through a selective but transient depletion of these lymphocyte subsets $[1,5]$, cladribine significantly reduces disease activity and disability progression in relapsing-remitting multiple sclerosis (RRMS) patients [2-4].

The SARS-CoV-2 pandemic has raised several concerns regarding the use of immunosuppressants in RRMS patients [6], since they are vulnerable to infections due to their disability and the use of drugs acting specifically on the immune system [7].

However, the influence of cladribine on the risk of developing COVID-19 disease is still unclear. Only two case series with three RRMS patients reported no or mild COVID-19 disease [8] or moderate pneumonia [9].

Here, we evaluated the prevalence and clinical features of COVID-19 disease among RRMS patients treated with cladribine in our center in Lombardy, Italy. From the whole MS population of our center, those treated with cladribine (Table 1) were asked if they had developed manifestations suggestive of COVID-19 disease up to August 25th 2020. Detailed demographic, clinical, and laboratoristic characteristics were collected.

Massimo Filippi

filippi.massimo@hsr.it

1 Neuroimaging Research Unit, Institute of Experimental Neurology, Division of Neuroscience, IRCCS San Raffaele Scientific Institute, Milan, Italy

2 Neurology Unit, IRCCS San Rafaele ScientiicInstitute, Milan, Italy

3 Neurorehabilitation Unit, IRCCS San Raffaele Scientific Institute, Milan, Italy

4 Neurophysiology Unit, IRCCS San Raffaele Scientific Institute, Milan, Italy

5 Vita-Salute San Raffaele University, Milan, Italy

\section{Case report}

Since the pandemic start, 2/56 (3.6\%) RRMS treated with cladribine complained a symptomatology suggestive of COVID-19 disease.

The first RRMS patient is a 30-year-old male, with a short disease duration (1.4 years), mild disability (Expanded Disability Status Scale [EDSS] score $=1.5$ ), and no comorbidities (Table 2). He started cladribine on January 10th 2020. One week later, he developed fever $\left(<37.5^{\circ}\right)$, ageusia, cough, fatigue, sputum production, sore throat, nasal congestion, shortness of breath without desaturation, and conjunctivitis. Serology for SARS-CoV-2 was negative in May 2020. Blood examinations performed before and after COVID-19 disease were within normal limits, except for a mild lymphopenia $\left(0.9^{*} 10^{\wedge} 9 /\right.$ liter $)$ after cladribine administration.

The second RRMS patient is a 40-year-old female with a disease duration of 13.4 years, moderate disability $($ EDSS $=3.5$ ), and no comorbidities (Table 2). She started cladribine on February 13th 2020 and underwent the second week of the first treatment course from March 5th 2020. On March 30th, she developed fever $\left(<37.8^{\circ}\right)$, anosmia, ageusia, cough, fatigue, and bone/joint pain. Serology for SARS-CoV-2 performed in May 2020 was positive. Blood examinations both before and after COVID-19 disease were normal.

Both patients stayed at home, were telephone-monitored by their neurologists, and fully recovered within 2 weeks. Unfortunately, both patients did not perform nasal swabs during the symptomatic phase of COVID-19 disease.

\section{Discussion}

In line with recent reports [8-11], only a minority of RRMS patients receiving cladribine $(2 / 56,3.6 \%)$ developed a mild and self-limiting COVID-19 disease. This prevalence was similar to that of the whole MS population of our center 
Table 1 Main demographic and clinical characteristics of RRMS patients treated with cladribine in our center

\begin{tabular}{ll}
\hline Variable & $\begin{array}{l}\text { Cladribine-treated RRMS } \\
\text { patients in our center } \\
(n=56)\end{array}$ \\
\hline Male/female (\%) & $17(30 \%) / 39(70 \%)$ \\
Mean age (SD) [years] & $33.8(8.1)$ \\
Median disease duration (IQR) [years] & $5.2(2.1-11.1)$ \\
Median EDSS (IQR) & $1.5(1.0-2.0)$ \\
$\begin{array}{l}\text { Median treatment duration* (IQR) } \\
\text { [months] }\end{array}$ & $15.8(12.9-20.5)$ \\
\hline
\end{tabular}

*at the last available follow-up (August 25th 2020)

EDSS Expanded Disability Status Scale; $I Q R$ interquartile range; $R R M S$ relapsing-remitting multiple sclerosis; $S D$ standard deviation

(84/2950, 2.8\%). Of note, at August $25^{\text {th }} 2020$, nasal/pharyngeal swabs have been found positive in $0.98 \%$ of the Lombardy population.

Although cladribine treatment is associated with peripheral lymphocyte depletion [5], our findings are consistent with data from randomized-controlled trials [12], showing that infections with cladribine are infrequent and, typically, self-limiting.

It is noteworthy that, in our cohort, COVID-19 disease occurred only in two RRMS patients close to treatment course and the possible nadir of selective immunosuppression. Accordingly, cladribine treatment could be safe during the COVID-19 pandemic. However, some precautions are needed during the first weeks after cladribine administration, when the risk of SARS-COV-2 infection could be higher due to transient immunosuppression. Further studies are necessary to evaluate whether cladribine could also prevent the cytokine storm associated with the most severe manifestations of COVID-19 disease [13].

In conclusion, young RRMS patients treated with cladribine, without comorbidities and with transitory systemic immunosuppression, are likely to show a risk of COVID-19 infection and complications that are similar to the general population.

Table 2 Main demographic, clinical, and laboratoristic findings of RRMS patients treated with cladribine and developing COVID-19 disease

\begin{tabular}{|c|c|c|c|c|}
\hline Variable & \multicolumn{2}{|l|}{ Case \#1 } & \multicolumn{2}{|l|}{ Case \#2 } \\
\hline Sex & \multicolumn{2}{|l|}{ Male } & \multicolumn{2}{|l|}{ Female } \\
\hline Age [years] & \multicolumn{2}{|l|}{30.5} & \multicolumn{2}{|l|}{40.0} \\
\hline Disease duration [years] & \multicolumn{2}{|l|}{1.4} & \multicolumn{2}{|l|}{13.4} \\
\hline EDSS & \multicolumn{2}{|l|}{1.5} & \multicolumn{2}{|l|}{3.5} \\
\hline Comorbidities & \multicolumn{2}{|l|}{ No } & \multicolumn{2}{|l|}{ No } \\
\hline \multirow[t]{2}{*}{ Treatment duration [months] } & At COVID-19 onset & $\begin{array}{l}\text { At the last FU } \\
\text { (Aug 25th } \\
\text { 2020) }\end{array}$ & At COVID-19 onset & At the last FU (Aug 25th 2020) \\
\hline & 0.2 & 7.6 & 1.5 & 6.8 \\
\hline Blood exams & $\begin{array}{l}\text { Before COVID-19 } \\
\text { (Dec 21st 2019) }\end{array}$ & $\begin{array}{l}\text { After COVID- } \\
19 \text { (Jan } \\
31 \text { st 2020) }\end{array}$ & $\begin{array}{l}\text { Before COVID-19 (Mar } \\
\text { 3rd 2020) }\end{array}$ & After COVID-19 (Apr 20th 2020) \\
\hline Leukocytes $\left(* 10^{\wedge 9 / L}\right)$ & 6.27 & 7.80 & 10.10 & 8.40 \\
\hline Neutrophils $\left(* 10^{\wedge} 9 / \mathrm{L}\right)$ & 2.81 & 5.90 & 7.10 & 5.00 \\
\hline Lymphocytes $\left(* 10^{\wedge} 9 / \mathrm{L}\right)$ & 1.96 & 0.90 & 2.10 & 1.80 \\
\hline $\mathrm{CD} 3+(\%)$ & N.A & $65.8 \%$ & N.A & N.A \\
\hline $\mathrm{CD} 3+/ \mathrm{CD} 4+(\%)$ & N.A & $42.8 \%$ & N.A & N.A \\
\hline $\mathrm{CD} 3+/ \mathrm{CD} 8+(\%)$ & N.A & $20.5 \%$ & N.A & N.A \\
\hline $\mathrm{CD} 20+(\%)$ & N.A & $11.4 \%$ & N.A & N.A \\
\hline
\end{tabular}

EDSS Expanded Disability Status Scale; $F U$ follow-up; $L$ liter; $N . A$. not available; $R R M S$ relapsing-remitting multiple sclerosis 
Author contributions PP: study concept, data gathering, drafting, and revising the manuscript. MAR: study concept, data gathering, drafting, and revising the manuscript. AN: data gathering and revising the manuscript. LM: data gathering and revising the manuscript. MF: study concept, data gathering, drafting, and revising the manuscript.

Funding No targeted funding reported.

\section{Compliance with ethical standards}

Conflicts of interest P. Preziosa received speakers honoraria from Biogen Idec, Novartis, Merck-Serono, and ExceMED. M.A. Rocca received speakers honoraria from Biogen Idec, Novartis, Genzyme, Teva, MS, R, Celgene, and Bayer, and receives research support from the MS Society of Canada and Fondazione Italiana Sclerosi Multipla. A. Nozzolillo has nothing to disclose. L. Moiola has received honoraria from Companies Biogen, Roche, TEVA, Sanofi, Serono, and Novartis. MF is Editor-in-Chief of the Journal of Neurology; received compensation for consulting services and/or speaking activities from Bayer, Biogen Idec, Merck-Serono, Novartis, Roche, Sanofi Genzyme, Takeda, and Teva Pharmaceutical Industries; and receives research support from Biogen Idec, Merck-Serono, Novartis, Roche, Teva Pharmaceutical Industries, Italian Ministry of Health, Fondazione Italiana Sclerosi Multipla, and ARiSLA (Fondazione Italiana di Ricerca per la SLA).

Ethics approval This study has been approved by the local ethics committee and has been performed in accordance with the ethical standards laid down in the 1964 Declaration of Helsinki and its later amendments.

Consent to participate All patients provided consent to be anonymously included in this report.

Consent for publication All authors have consented to publication.

Availability of data and material Not applicable.

\section{References}

1. Giovannoni G (2017) Cladribine to treat relapsing forms of multiple sclerosis. Neurotherapeutics 14(4):874-887

2. Giovannoni G, Comi G, Cook S, Rammohan K, Rieckmann P, Soelberg Sorensen P et al (2010) A placebo-controlled trial of oral cladribine for relapsing multiple sclerosis. N Engl J Med 362(5):416-426

3. Giovannoni G, Soelberg Sorensen P, Cook S, Rammohan K, Rieckmann P, Comi G et al (2018) Safety and efficacy of cladribine tablets in patients with relapsing-remitting multiple sclerosis: results from the randomized extension trial of the CLARITY study. Mult Scler 24(12):1594-1604

4. Leist TP, Comi G, Cree BA, Coyle PK, Freedman MS, Hartung HP et al (2014) Effect of oral cladribine on time to conversion to clinically definite multiple sclerosis in patients with a first demyelinating event (ORACLE MS): a phase 3 randomized trial. Lancet Neurol 13(3):257-267

5. Comi G, Cook S, Giovannoni G, Rieckmann P, Sorensen PS, Vermersch P et al (2019) Effect of cladribine tablets on lymphocyte reduction and repopulation dynamics in patients with relapsing multiple sclerosis. Mult Scler Relat Disord 29:168-174

6. Brownlee W, Bourdette D, Broadley S, Killestein J, Ciccarelli O (2020) Treating multiple sclerosis and neuromyelitis optica spectrum disorder during the COVID-19 pandemic. Neurology 5:9

7. Winkelmann A, Loebermann M, Reisinger EC, Hartung HP, Zettl UK (2016) Disease-modifying therapies and infectious risks in multiple sclerosis. Nat Rev Neurol 12(4):217-233

8. De Angelis M, Petracca M, Lanzillo R, Brescia Morra V, Moccia M (2020) Mild or no COVID-19 symptoms in cladribine-treated multiple sclerosis: two cases and implications for clinical practice. Mult Scler Relat Disord 45:102452

9. Dersch R, Wehrum T, Fahndrich S, Engelhardt M, Rauer S, Berger B (2020) COVID-19 pneumonia in a multiple sclerosis patient with severe lymphopenia due to recent cladribine treatment. Mult Scler 1:352458520943783

10. Louapre C, Collongues N, Stankoff B, Giannesini C, Papeix C, Bensa $C$ et al (2020) Clinical characteristics and outcomes in patients with coronavirus disease 2019 and multiple sclerosis. JAMA Neurol 6:9

11. Sormani MP (2020) On behalf of the Italian Study Group on COVID-19 infection in multiple sclerosis. An Italian programme for COVID-19 infection in multiple sclerosis. Lancet Neurol 2020(7):56

12. Cook S, Leist T, Comi G, Montalban X, Giovannoni G, Nolting A et al (2019) Safety of cladribine tablets in the treatment of patients with multiple sclerosis: an integrated analysis. Mult Scler Relat Disord 29:157-167

13. Shi Y, Wang Y, Shao C, Huang J, Gan J, Huang X et al (2020) COVID-19 infection: the perspectives on immune responses. Cell Death Differ 27(5):1451-1454 